\title{
Determination of Performance Measuring Parameters of an Improved Dual Paraboloid Solar Cooker
}

\author{
Suhail Zaki Farooqui ${ }^{1,2}$ \\ ${ }^{1}$ US-Pakistan Center for Advanced Studies in Energy, University of Engineering \& Technology, Peshawar, Pakistan \\ ${ }^{2}$ Faculty of Engineering Sciences, PNEC, National University of Sciences \& Technology, Islamabad, H.I. Rahamatullah Road, \\ Karachi 75350, Pakistan
}

Correspondence should be addressed to Suhail Zaki Farooqui; drsuzaki@hotmail.com

Received 9 May 2017; Revised 15 June 2017; Accepted 20 June 2017; Published 7 August 2017

Academic Editor: Xinhai Xu

Copyright ( 92017 Suhail Zaki Farooqui. This is an open access article distributed under the Creative Commons Attribution License, which permits unrestricted use, distribution, and reproduction in any medium, provided the original work is properly cited.

An experimental investigation into the performance evaluation of an improved dual reflector foldable paraboloid solar cooker has been reported, along with its energy and exergy analysis. The best attribute of this lightweight and low-cost solar cooker is its high performance coupled with the ease of handling. The cooker utilizes two paraboloid reflectors made out of Mylar-coated fiberglass dishes, each having a diameter of $90 \mathrm{~cm}$ and focal length of $105 \mathrm{~cm}$. The total intercepted radiation energy is $1.08 \mathrm{~kW}$ under standard test conditions. Stagnation temperatures of up to $330^{\circ} \mathrm{C}$ and cooking temperatures of up to $290^{\circ} \mathrm{C}$ have been attained with load. Altogether, 9 experiments have been performed with and without load. Loaded tests have been conducted with water and vegetable oil. Results indicate an average cooking power of $485 \mathrm{~W}$, peak exergy gain of $60.53 \mathrm{~W}$, quality factor of 0.077 , and a high product of temperature difference gap at half peak power to peak power of $4364.33 \mathrm{~W} \cdot \mathrm{K}$. The maximum exergy output power attained was $70 \mathrm{~W}$, while maximum exergy efficiency was $8-10 \%$. All performance measuring parameters indicate that it is a high performance solar cooker for rural and urban communities and is suitable for all types of oil- and water-based cooking.

\section{Introduction}

Development of more efficient and user friendly solar cookers is a high priority area, as cooking of food accounts for a substantially large chunk of the total fuel consumption on Earth. In case of the developing countries, this activity accounts to over one-third of the total primary fuel consumption $[1,2]$. Conversion of cooking to renewables has the potential of substantially reducing the fuel bills of many energy-deficient countries of the world, as well as reducing the greenhouse gas emissions. Three broad types of solar cookers have been reported in the literature during the last over half a century. Box-type solar cookers utilizing the greenhouse effect to acquire the cooking temperatures are so far the most popular ones, due mainly to their simplicity and lower costs. However, they suffer from the main disadvantage of approaching the maximum temperatures of around $120^{\circ} \mathrm{C}$. Therefore, they are suitable only for waterbased low temperature cooking $[3,4]$. Oil-based high temperature cooking is not possible with these cookers. Parabolic types are the second most common solar cookers. Typically, they utilize a parabolic reflector mounted near the ground, which focuses the reflected solar radiation onto a cooking pan placed at a height. Generally, these cookers acquire high cooking temperatures suitable for cooking all types of food. However, they suffer from a number of issues, including the requirement of frequent solar tracking, lack of maneuverability due to larger sizes and weights, and the splashes of oil and curry falling onto the reflector, requiring frequent cleaning and adversely affecting its reflectivity. The third main type of solar cookers are the vacuum tube-based cookers, as presented by various authors [1,3-7]. Though these cookers acquire high temperatures and are very efficient, they are complex to operate and expensive to manufacture.

Parabolic-type solar cookers have been offered in several versions by a number of authors. Typically, these cookers acquire concentration ratios of up to 50 and temperatures of up to $300^{\circ} \mathrm{C}$ [8]. With a spherical reflector, the first design was proposed by Stam in 1961 [2]. It was the simplest type of reflector, allowing the cooking vessel to be hung 
from a tripod at a suitable focal point. However, due to the spherical shape of the reflector, the focus was not very good. A parabolic reflector-type cooker named as SK-14 was invented by Dr. Dieter Seifert $[9,10]$. The focus of this cooker was much better and sharper than the previous one. However, it is very sensitive to even a slight change in the position of the sun and hence it requires constant tracking. Due to its deeply curved parabolic reflectors, the focal point lies inside the dish $[11,12]$. Further, due to the usage of a single large dish, it occupies more space, making it difficult to carry from one place to the other. Also, the frequent oil and curry splashes spoil the reflector surface, as the cooking utensils are placed above the parabolic reflector. Making this type of cooker requires advanced manufacturing facilities available only to large companies.

The Sheffler community solar cooker was invented by Wolfgang Sheffler in 1986 [13, 14]. The Sheffler-type solar cookers utilize large flexible parabolic mirrors to concentrate the solar radiation inside a kitchen on a fixed point through a North-facing window, where high temperatures of up to $1000^{\circ} \mathrm{C}$ are attainable to cook all types of food. The polar directional controls of the parabolic mirrors are carried out through clockwork rotation at the rate of one revolution per day. The reflector is made to change the shape of its entire surface every few days to adapt itself to the changing declination angles of the sun. For these reasons, its design, manufacturing, and installation are complex. Further, it requires heavy and robust permanent structure for its support and installation needs shadow-free area throughout the year in the south direction. The requirement for capital investment is also high. Some authors have also evaluated the compound parabolic reflectors which do not require solar tracking for a few hours $[15,16]$. However, these are not suitable for use with solar cookers due to their bulky size, complex construction, and use of large quantities of thermal fluids, causing delayed heating.

In this paper, the design and working scheme of a dual reflector parabolic cooker has been described and experimentally tested with an aim to address the abovementioned deficiencies noted in this class of cookers. A lightweight cooker with two foldable fiberglass parabolic reflectors coated with Mylar sheet has been introduced. These attributes make it convenient to move the cooker from one place to the other, operate at any desired place, and easily store inside the home when not in use. A number of simple controls have been provided to change the inclination of each individual reflector, as well as the collective inclination of both the reflectors, in order to maintain the focused radiation from both the reflectors onto the cooking pan, with changing positions of the sun on the sky. Further, sufficient separation has been provided between the two reflectors to allow any oil and curry splashed from the cooking pan to fall onto the ground, rather than damaging the reflector surfaces. Support for the cooking pan has been kept separate to allow easy maneuverability of the cooker and to prevent shaking of the cooking utensils, while the reflective mirrors are adjusted.

Several experiments have been conducted without load and with load of $4 \mathrm{~kg}$ of water, as well as vegetable oil to extract the various performance measuring parameters. The experimental results are analyzed in each case for determining the first and second figures of merit, cooking power, energy and exergy efficiencies, and the quality factor of the cooker.

The first figure of merit $F_{1}$ measures the optical efficiency of the cooker per unit heat loss factor. This is measured by dividing the difference of the maximum temperature attained by the unloaded bottom of the cooker with the ambient air temperature to the average solar radiation intensity during experiment. The second figure of merit $F_{2}$ gives an indication of heat transfer from the absorbing base to the water inside the cooker. It is evaluated in the presence of full load, as the product of heat gained by water and $F_{1}$ per unit aperture area per unit time per unit temperature. The cooking power is the heat gained by the water inside the cooker per unit time. Energy efficiency of the cooker is evaluated as the heat gained by the water inside the cooker divided by the solar radiation energy intercepted by the cooker collector during a given time. The exergy efficiency measures the potential of the cooker to extract the solar radiation energy. This is obtained by dividing the exergy output of the cooker by the exergy input. The exergy input and output are evaluated by recording the ambient air and water temperatures and solar radiation intensity after periodic intervals of time, while considering the water content, aperture area of the cooker, and the temperature of the surface of the sun, using formulas described in (4) and (5). The quality factor of the cooker is determined by dividing the peak exergy gain of the cooker with the exergy loss (the difference between exergy input and output) at that instant of time. The peak exergy gain is obtained by plotting the exergy output versus the temperature difference of water with the ambient air. The curve is fitted with a second order polynomial, and peak is determined.

\section{The Optical Scheme of the Dual Paraboloid Reflector}

A paraboloid reflector is defined to provide a sharp focus to the rays of light reflected from its surface, when the incident light consists of rays parallel to the axis of the paraboloid. If the incident light is not parallel to the axis of the paraboloid, the reflected light does not make a sharp focus at the focal point, but rather a dispersed focus at a point other than the focal point, as shown in Figure 1 [17].

Since the cooking pan has finite dimensions, the need for a sharp focus is not quite critical and the cooker can benefit even from a dispersed focus of the incident light reflected from the two paraboloids placed at a distance from each other, without much significant loss of performance. This feature enables the two paraboloids to get folded when not in use, making it handy to allow easy movement and storage of the cooker. Further, it allows the oil and curry splashes to mostly fall on the ground, rather than spoiling the central part of the reflective surface. The paraboloids used in the above scheme have a focal length of $105 \mathrm{~cm}$ and a radius of $45 \mathrm{~cm}$. The distance between the rims of the two paraboloids is $20 \mathrm{~cm}$. Therefore, the angle of incidence of the solar radiation to the axis of each paraboloid is 
Cooking pan placed over dispersed focus

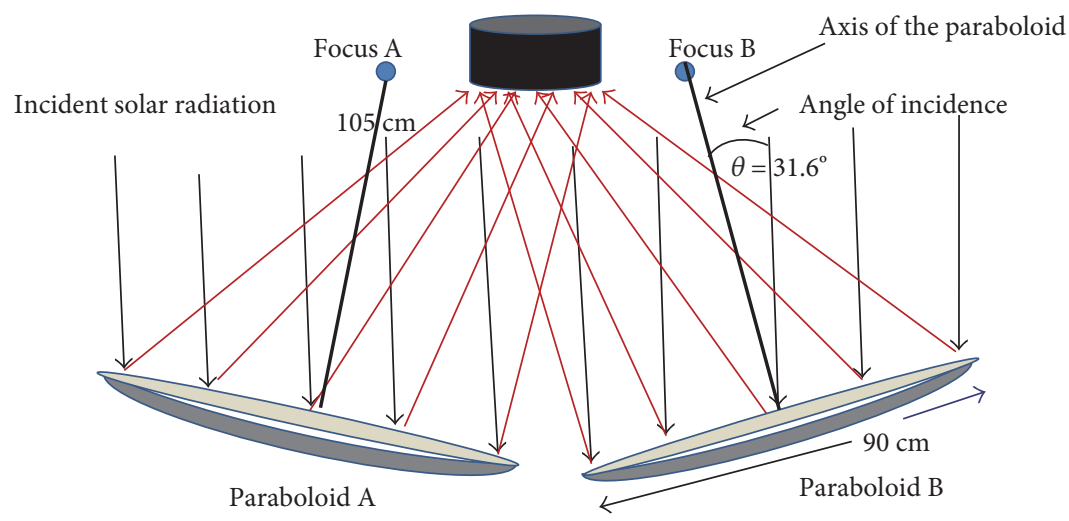

Figure 1: Optical scheme of the light reflected from a dual paraboloid reflecting system defining a dispersed focus.

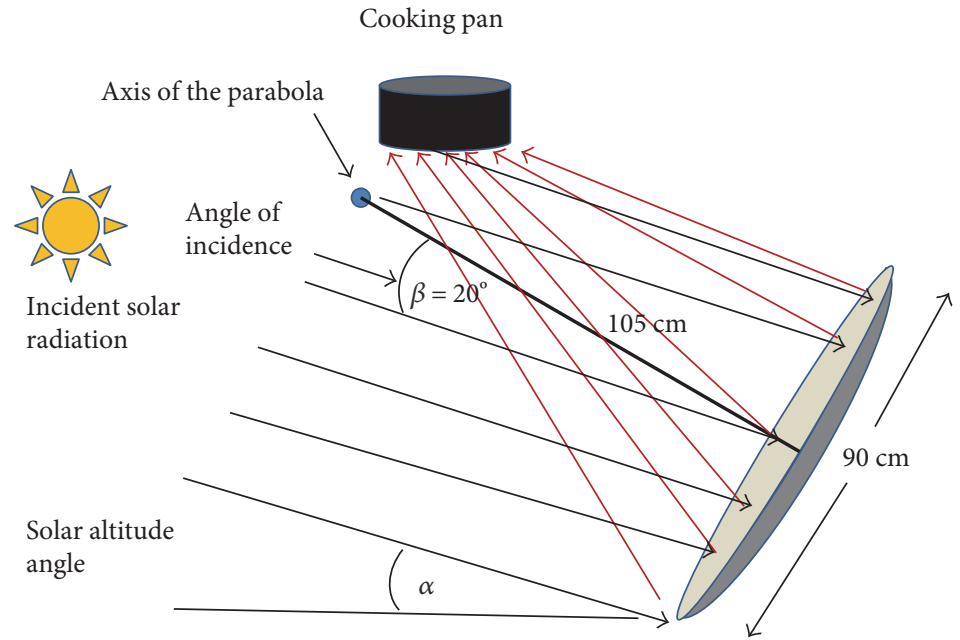

FIgURE 2: Operational scheme of the dual paraboloid reflector to cater for the changing altitude angle of the sun.

$\sin ^{-1}(55 / 105)=31.6^{\circ}$. Further, the altitude angle of the two paraboloids would not, in general, be the same during operation as that of the sun at any instant of time, since the height of the cooking pan is held fixed during operation while the altitude angle of the sun changes. The cooking pan is not placed vertically above the reflectors, as shown in Figure 2. Normally, there would be a difference of nearly 10-20 between the two angles during 9:00 to 15:00 hours, depending upon the season. The total maximum cosine losses due to the difference between the angle of incidence of the solar radiation and the axes of the paraboloids are therefore $\leq\left[1-\cos \left(31.6^{\circ}\right) \cdot \cos \left(20^{\circ}\right)\right]=20 \%$.

\section{The Dual Paraboloid Reflector Solar Cooker}

The complete dual parabolic reflector solar cooker has been constructed in five pieces. Four of them are connected together to make one piece, while the fifth piece is kept separate to make the handling of the cooker easier. Two identical paraboloids made out of fiberglass having diameter of $90 \mathrm{~cm}$ and focal length of $105 \mathrm{~cm}$ each have been used. The inner surfaces of the paraboloids have been coated with highly reflective Mylar sheet. The sheet has a reflectivity of $94 \%$ and can withstand temperatures of up to $200^{\circ} \mathrm{C}$ [18]. Two pipe frames $\mathrm{A}$ and $\mathrm{B}$ are constructed as shown in Figure 3. Two steel pipes are bent in circles of diameter $75 \mathrm{~cm}$ each. Two small pieces of pipes "a1" are welded with frame A on one side, while another $17.5 \mathrm{~cm}$ long pipe "a2" is perpendicularly welded to them on the other side. A small rod passing through a small piece of pipe attached to an eye is welded between the small pieces of pipes, so that the pipe containing the eye can easily rotate with respect to the rod. The eye contains a threaded nut that allows a bolt to pass through. The bolt pressing against a closed ended U-channel on another frame provides a simple control for changing the orientation of the parabolic reflector, while in operation. The frame B is also similarly constructed with different distance between the pipes "b1." Whole scheme is illustrated in Figure 3.

The parabolic reflector frames A and B are then mounted on another frame through a rotational axis rod, as shown in Figure 4 . The rotational axis rod passes through the pipes 


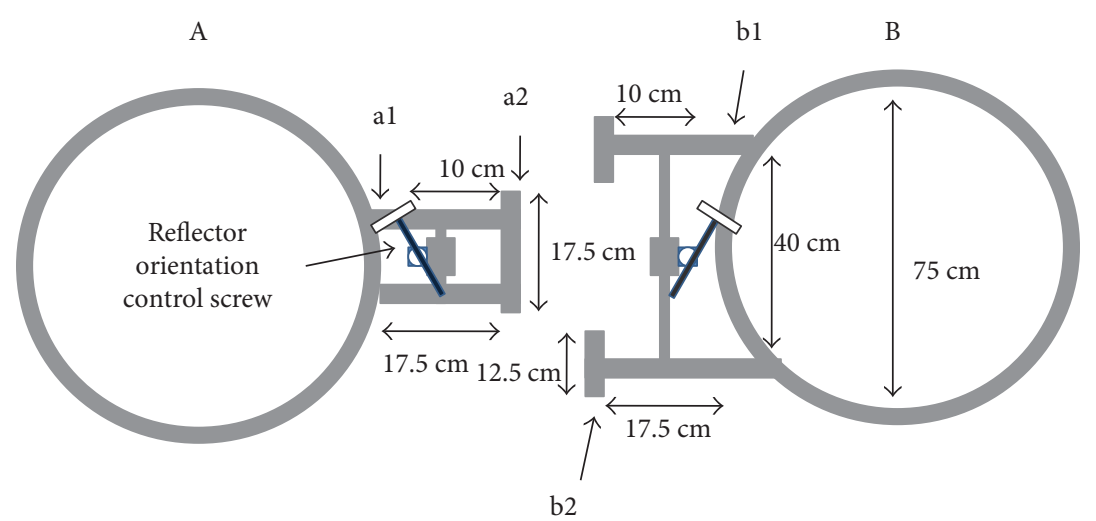

Figure 3: Schematic diagram of the dual parabolic reflector support system with dimensions.

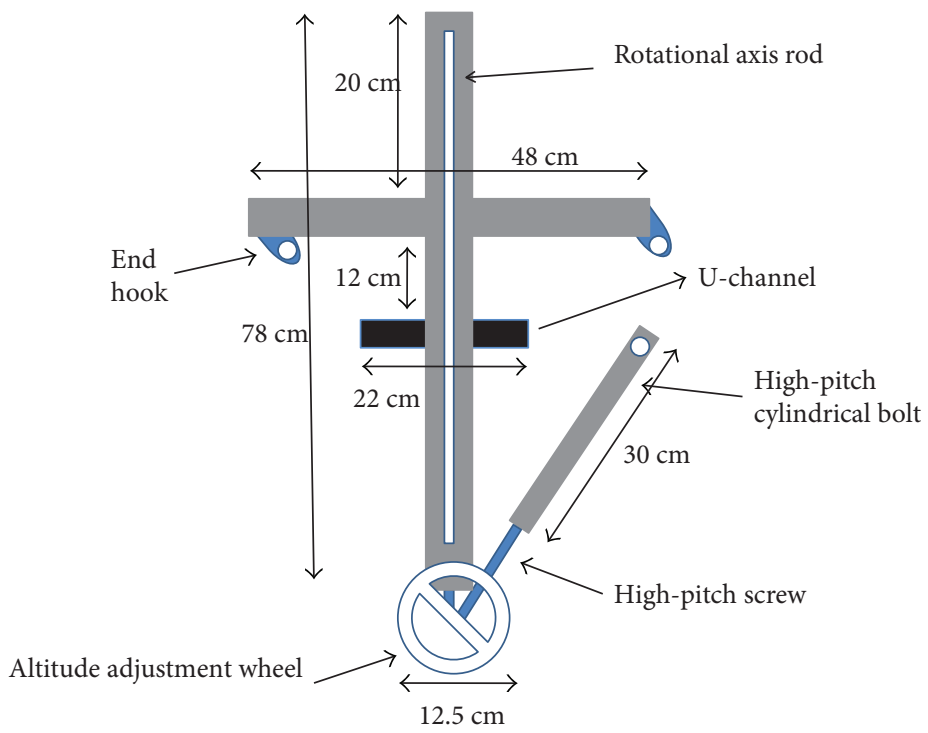

FIGURE 4: Schematic diagram of the frame allowing the orientation control of the parabolic reflectors along the altitude.

"a2" and "b2" of frames "A" and "B" and allows both frames to rotate with respect to it. This allows both reflectors to be adjusted, such that the reflected solar radiation gets focused below the coking pan, within an area equal to the diameter of the pan.

The frame shown in Figure 4 consists of a $78 \mathrm{~cm}$ long rectangular pipe, cross welded with another piece of $48 \mathrm{~cm}$ long pipe and a $22 \mathrm{~cm}$ long closed end U-channel. The $48 \mathrm{~cm}$ long pipe contains one strut with an eye hole at each end. The whole frame can rotate with respect to a rod passing through these struts. The rear end of this frame is connected to an altitude adjustment wheel, which can drive a high-pitch screw into a similarly pitched $30 \mathrm{~cm}$ long bolt. The next end of this bolt is connected to another frame, such that rotating the altitude adjustment wheel allows the whole frame to change its orientation with respect to the rod passing through the abovementioned two struts. This rod is welded onto the frame shown in Figure 5.

The Y-shaped frame shown in Figure 5 is made out of four rectangular pipe sections. Five wheels are connected at the ends of the frame. The frame in Figure 4 is connected to this frame through the $53 \mathrm{~cm}$ long welded rod and a hook, as shown. This frame supports the entire structure of the cooker and can be easily moved across over a flat surface. The total weight of the entire structure with fiberglass dishes is $12 \mathrm{~kg}$.

The last part of the cooker is the cooking pan holder. The holder frame made out of angle iron, shown in Figure 6, is $125 \mathrm{~cm}$ high, $60 \mathrm{~cm}$ long, and $37.5 \mathrm{~cm}$ wide and provides a structurally stable support for the cooking pan. The bottom of this frame is slipped between the two front wheels of the frame shown in Figure 5, such that any movement of the reflector frame does not cause any vibrations onto the cooking frame.

The complete dual parabolic reflector cooker in operation is shown in Figure 7.

\section{Performance Measuring Experiments}

Several experiments had been performed on carefully selected calm and clear days at $33.73^{\circ} \mathrm{N}$ latitude and $73.09^{\circ} \mathrm{E}$ longitude test location (Islamabad, Pakistan), during the 


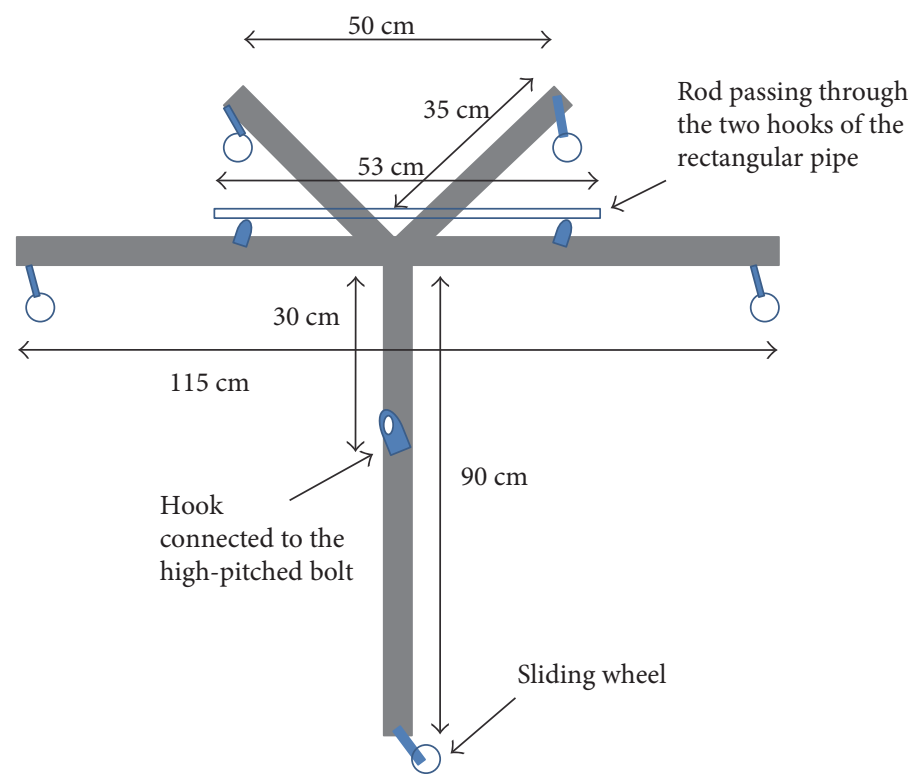

FIGURE 5: Schematic diagram of the Y-shaped support frame, placed on a level surface.

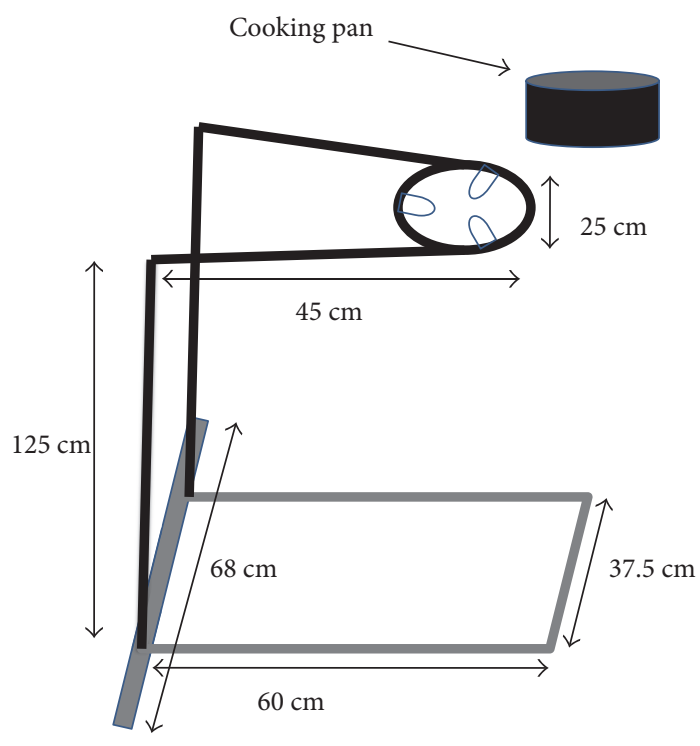

Figure 6: Cooking pan holding frame.

months of April and May 2016, to assess the performance measuring parameters of the dual parabolic reflector solar cooker, described in the previous section. Three experiments were performed on different days without load to determine the maximum plate stagnation temperature and the first figure of merit $F_{1}$. Three more experiments were performed with $4 \mathrm{~kg}$ of water load each, to determine the energy and exergy efficiencies of the cooker, the second figure of merit $F_{2}$, cooking power, and the quality factor of the cooker. Further, three experiments were performed with cooking oil load to determine the maximum achievable temperatures with load, as shown in Table 1 . The recorded data included the ambient temperature $T_{\mathrm{a}}$, plate temperature $T_{\mathrm{p}}$, load temperature $T_{1}$, and the solar radiation intensity $I_{\mathrm{h}}$ on the

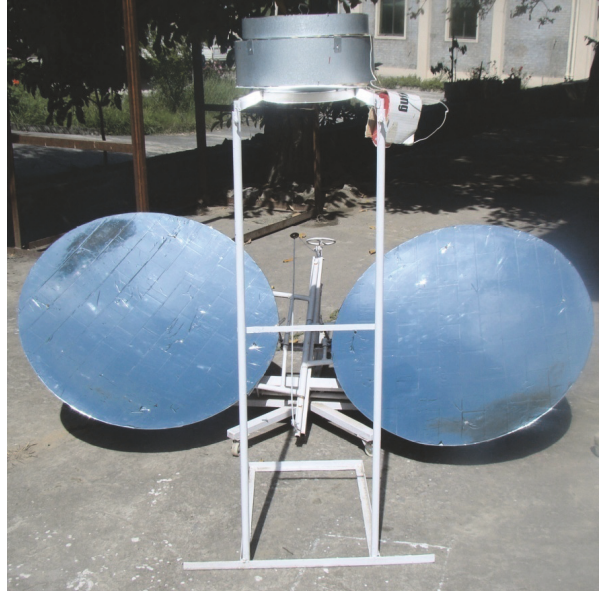

FIGURE 7: The dual parabolic reflector solar cooker in operation.

horizontal surface. The maximum available power to the cooker through two reflectors (diameter $90 \mathrm{~cm}$ each) under standard solar insolation conditions of $1000 \mathrm{~W} / \mathrm{m}^{2}$, while taking into account the cosine losses, is $1.08 \mathrm{~kW}$. The cooking pot had a diameter of $25 \mathrm{~cm}$ and could accommodate up to 7 liters of liquid load. It was surrounded from all sides with a $5 \mathrm{~cm}$ thick glass wool insulation. The lid at the top was also covered with a $5 \mathrm{~cm}$ thick layer of glass wool. The insulation-free bottom of the pot was exposed to the ambient air and was sprayed with dull black deco paint. Nine experiments had been performed with corresponding conditions as outlined in Table 1.

The first set of experiments was performed without load on the cooker. The base plate temperature of the cooker, the ambient temperature, and the solar radiation intensity on a horizontal surface were measured and recorded every two minutes, while cooker tracking adjustments were 
TABLE 1: Test conditions of nine experiments.

\begin{tabular}{|c|c|c|c|c|c|}
\hline Exp. number & Date of experiment & $\begin{array}{c}\text { Experiment start solar } \\
\text { time }(\mathrm{H}: \mathrm{M})\end{array}$ & $\begin{array}{l}\text { Experiment end } \\
\text { solar time }(\mathrm{H}: \mathrm{M})\end{array}$ & Load (gm) & $\begin{array}{l}\text { Max. temp. } \\
\text { attained }\left({ }^{\circ} \mathrm{C}\right)\end{array}$ \\
\hline 1 & April 13, 2016 & 09:40 & $10: 30$ & Nil & 233 \\
\hline 2 & April 13, 2016 & $12: 18$ & $12: 46$ & Nil & 258 \\
\hline 3 & April 22, 2016 & $11: 26$ & $12: 18$ & Nil & 331 \\
\hline 4 & April 14, 2016 & $13: 46$ & $14: 14$ & 4000 (water) & 100 \\
\hline 5 & May 02, 2016 & $12: 16$ & 13:04 & 4000 (water) & 100 \\
\hline 6 & May 18, 2016 & $12: 24$ & $12: 58$ & 4000 (water) & 100 \\
\hline 7 & April 22, 2016 & $12: 06$ & $12: 44$ & 850 (oil) & 294 \\
\hline 8 & April 27, 2016 & $10: 56$ & $12: 00$ & 850 (oil) & 262 \\
\hline 9 & April 29, 2016 & $11: 04$ & $12: 00$ & 850 (oil) & 285 \\
\hline
\end{tabular}

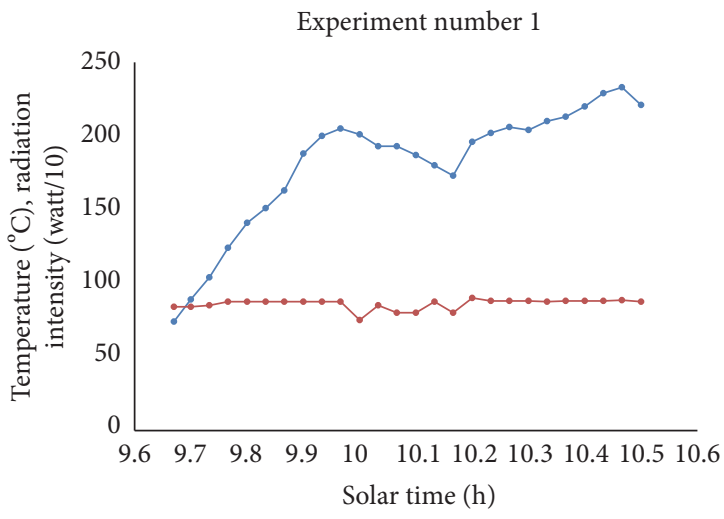

FIgUre 8: Plot of temperature (blue) and solar radiation intensity (red) versus time for the first unloaded experiment. Radiation intensity is divided by 10 to fit the scale.

performed every five minutes. Digital thermometers UT33 series, prepared by Uni-Trend Group Ltd., China, were used for temperature measurement, while Apogee SP110 pyranometer was used for the measurement of solar radiation intensity. The data plotted in Figures 8, 9, and 10 indicates the stagnation temperatures attained in each case.

The blue curves in Figures 8, 9, and 10 show that the maximum temperatures attained during the three unloaded experiments were $233^{\circ} \mathrm{C}, 258^{\circ} \mathrm{C}$, and $331^{\circ} \mathrm{C}$, respectively. A comparison of these figures shows that the maximum plate temperature depends heavily on the existing intensity of the solar radiation.

The second set of experiments was conducted with a load of $4 \mathrm{~kg}$ of water each time, on April 14, May 2, and May 18, 2016, as per the recommended test load for solar cookers per unit aperture area per unit concentration ratio [19]. As shown in Figures 11, 12, and $13,4 \mathrm{~kg}$ of water load was brought to a boil in 28 minutes, 48 minutes, and 34 minutes from starting temperatures of $42^{\circ} \mathrm{C}, 39^{\circ} \mathrm{C}$, and $36^{\circ} \mathrm{C}$, respectively.

The last set of experiments was conducted with one liter (850 gm) of vegetable oil load each time, on April 22, 27, and 29,2016. As shown in Figures 14, 15, and 16, the vegetable oil attained maximum temperatures of $294^{\circ} \mathrm{C}, 262^{\circ} \mathrm{C}$, and

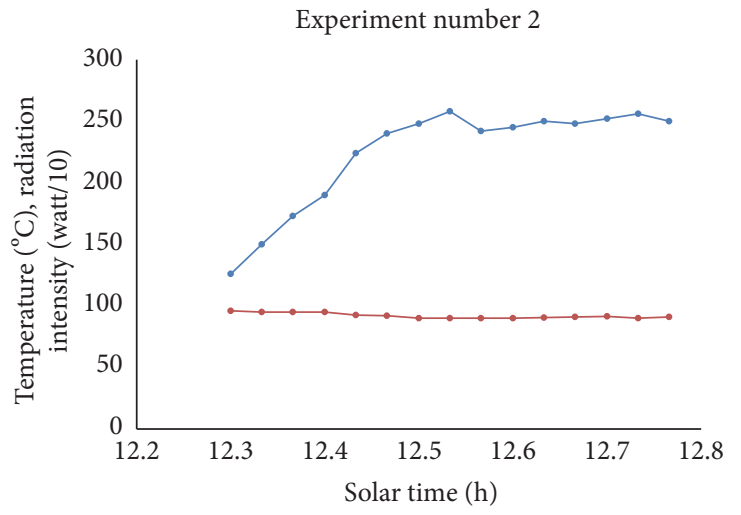

FIgURe 9: Plot of temperature (blue) and solar radiation intensity (red) versus time for the second unloaded experiment. Radiation intensity is divided by 10 to fit the scale.

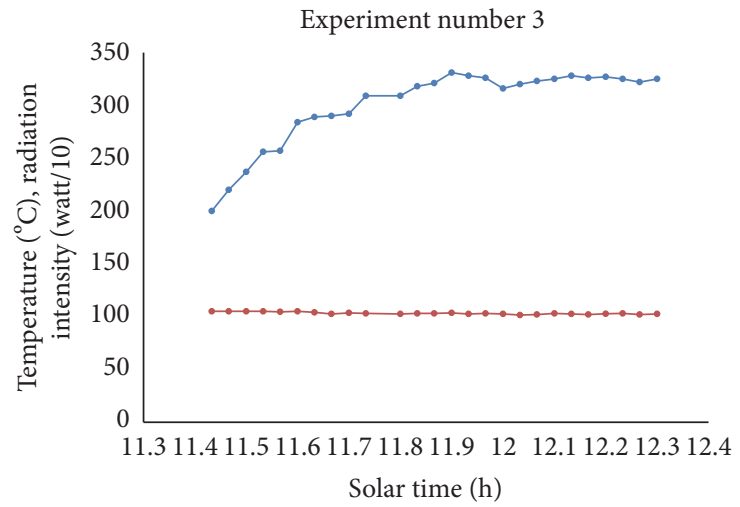

FIgURE 10: Plot of temperature (blue) and solar radiation intensity (red) versus time for the third unloaded experiment. Radiation intensity is divided by 10 to fit the scale.

$285^{\circ} \mathrm{C}$ in 38 minutes, 64 minutes, and 56 minutes from starting temperatures of $101^{\circ} \mathrm{C}, 60^{\circ} \mathrm{C}$, and $53^{\circ} \mathrm{C}$, respectively.

Results of three sets of three experiments each have been shown in the foregoing, with dual parabolic reflector soar cooker, during the months of April and May 2016. The experiments with no load on the cooker indicate that under 


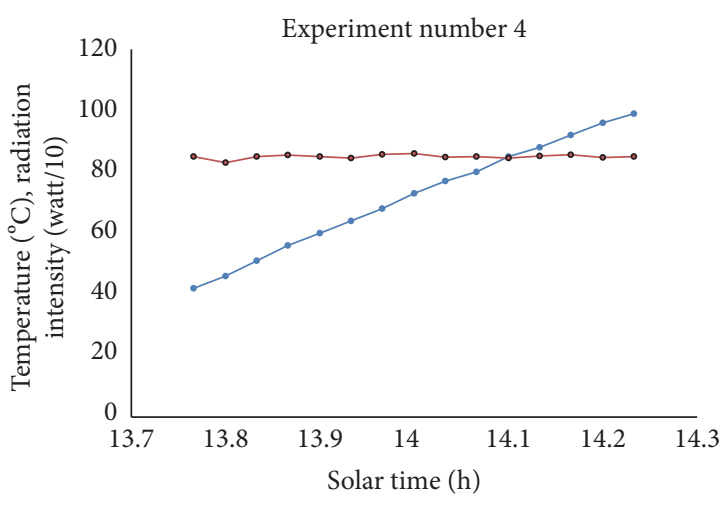

Figure 11: Plot of temperature (blue) and solar radiation intensity (red) versus time for the first experiment with $4 \mathrm{~kg}$ of water load. Radiation intensity is divided by 10 to fit the scale.

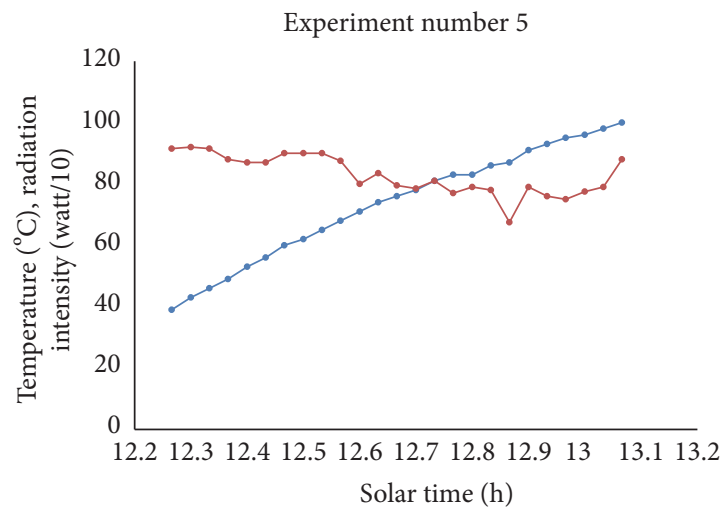

Figure 12: Plot of temperature (blue) and solar radiation intensity (red) versus time for the second experiment with $4 \mathrm{~kg}$ of water load. Radiation intensity is divided by 10 to fit the scale.

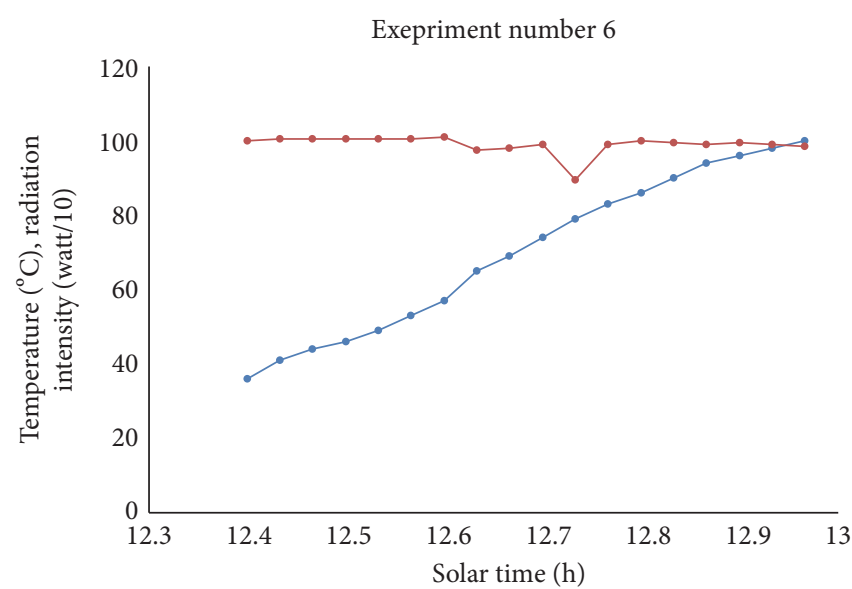

FIGURE 13: Plot of temperature (blue) and solar radiation intensity (red) versus time for the third experiment with $4 \mathrm{~kg}$ of water load. Radiation intensity is divided by 10 to fit the scale.

clear sky conditions, maximum plate temperatures as high as $330^{\circ} \mathrm{C}$ may be attained in 30 to 40 minutes duration. Experiments with $4 \mathrm{~kg}$ of water load indicate that starting from the

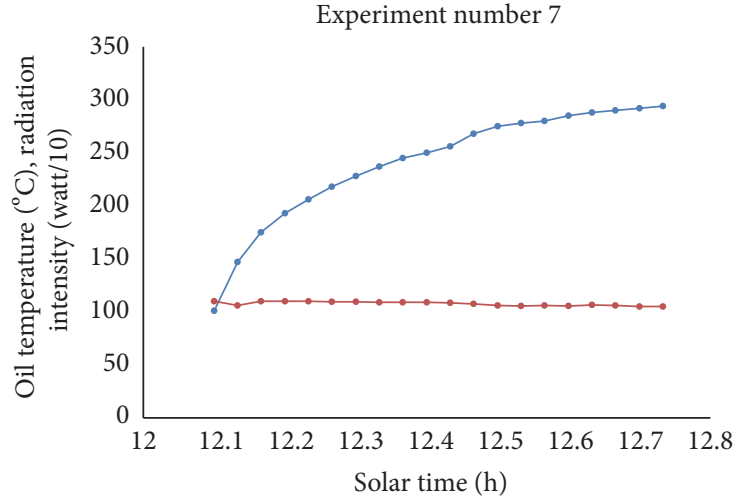

FIgURE 14: Plot of temperature (blue) and solar radiation intensity (red) versus time for the first experiment with $850 \mathrm{gm}$ of vegetable oil load. Radiation intensity is divided by 10 to fit the scale.

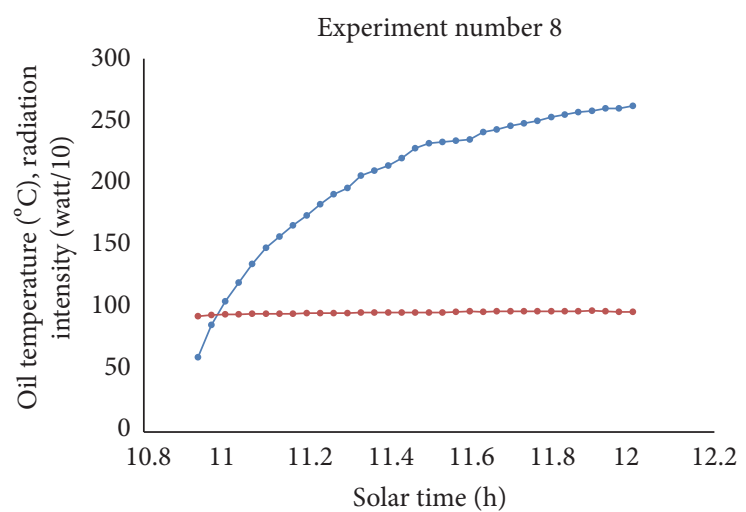

FIgURE 15: Plot of temperature (blue) and solar radiation intensity (red) versus time for the second experiment with $850 \mathrm{gm}$ of vegetable oil load. Radiation intensity is divided by 10 to fit the scale.

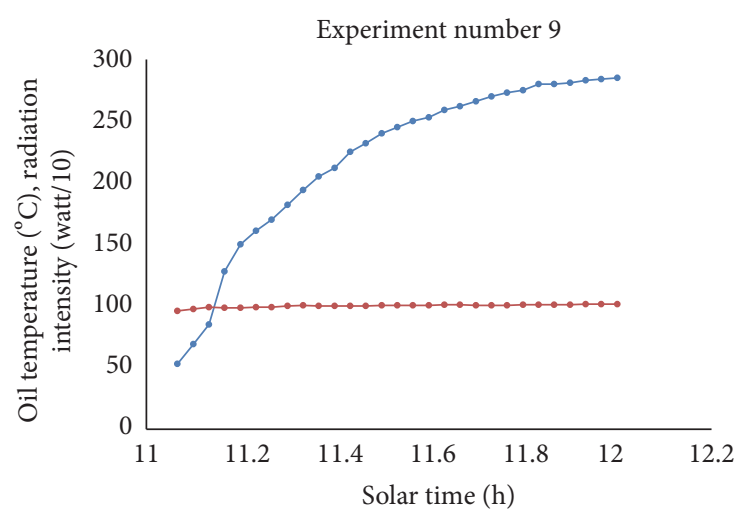

Figure 16: Plot of temperature (blue) and solar radiation intensity (red) versus time for the third experiment with $850 \mathrm{gm}$ of vegetable oil load. Radiation intensity is divided by 10 to fit the scale.

ambient temperatures, it boils in 28 to 48 minutes, depending upon the radiation intensity. The last set of experiments with vegetable oil load indicates the maximum attainable cooking temperatures with load. Temperatures as high as $294^{\circ} \mathrm{C}$ have been attained this way, with the average attained temperature 
of about $280^{\circ} \mathrm{C}$ in 53 minutes. All these results indicate that the cooker presented in this paper is most suitable for fulfilling the oil-based high-temperature cooking needs of the public, while being user friendly, lightweight, and low cost.

The detailed performance measuring parameters of the cooker have been evaluated in the following sections.

\section{Determination of the First and Second Figures of Merit}

In order to test the performance of solar cookers, two figures of merit (FOM) are normally recommended. These are defined as $F_{1}$ and $F_{2}[20,21] . F_{1}$ (measured in $\mathrm{m}^{2} \mathrm{~K} / \mathrm{W}$ ) is the ratio of optical efficiency to the heat loss factor by the bottom absorbing plate and is a measure of the differential temperature gained by it at a particular level of solar insolation. $F_{2}$ gives an indication of heat transfer from the absorbing base to the water inside the cooker.

Mathematically, they are defined as

$$
F_{1}=\frac{T_{\mathrm{ps}}-T_{\mathrm{a}}}{H_{\mathrm{s}}}
$$

where $T_{\mathrm{ps}}$ is the plate (tray) stagnation temperature, $H_{\mathrm{s}}$ is the solar insolation on the horizontal surface, and $T_{\mathrm{a}}$ is the ambient temperature.

$$
F_{2}=\frac{F_{1}(M \cdot C)_{\mathrm{w}}}{A \cdot \tau} \ln \frac{\left[1-\left(T_{\mathrm{wi}}-T_{\mathrm{a} v}\right) /\left(F_{1} \cdot H_{\mathrm{av}}\right)\right]}{\left[1-\left(T_{\mathrm{wf}}-T_{\mathrm{av}}\right) /\left(F_{1} \cdot H_{\mathrm{a} v}\right)\right]},
$$

where $(M \cdot C)_{\mathrm{w}}$ indicates the mass of the water in the pot multiplied to its heat capacity, $A$ stands for the aperture area of the cooker, $\tau$ is the time difference during which water was heated from an initial temperature $T_{\mathrm{wi}}$ to the final temperature $T_{\mathrm{wf}}, H_{\mathrm{av}}$ is the average solar radiation on a horizontal surface, and $T_{\mathrm{av}}$ is the average ambient temperature during the experiment. $F_{1}$ is evaluated in the absence of any load on the solar cooker while $F_{2}$ is evaluated in the presence of full load.

The cooking power of a cooker can be calculated as [21]

$$
P=(M \cdot C)_{\mathrm{w}}\left[\frac{\Delta T_{\mathrm{w}}}{\Delta t}\right]
$$

where $\Delta T_{\mathrm{w}}$ is the temperature difference of water acquired in time $\Delta t$.

For the unloaded solar cooker described in this paper, three experiments were conducted on April 13 and April 22, 2016. The $F_{1}$ calculation results are summarized in Table 2.

For the fully loaded (4 kg of water load) cooker, data were collected on April 14, May 2, and May 18, 2016. For analysis, data are used for the water temperatures between 60 and $90^{\circ} \mathrm{C}$, for each experiment. The results are summarized in Table 3.

From the results in Tables 2 and 3, it is concluded that the average value of the first figure of merit $F_{1}$ is 0.2578 , while that of the second figure of merit $F_{2}$ is 0.567 . The average cooking power of the solar cooker is $485 \mathrm{~W}$. For comparison, the typical value of $F_{1}$ is $0.103, F_{2}$ is 0.309 , and the cooking
TABLE 2: Calculation of the first figure of merit for the dual parabolic reflector solar cooker during experiment numbers 1,2 , and 3 .

\begin{tabular}{lcccc}
\hline Exp. number & $T_{\mathrm{as}}\left({ }^{\circ} \mathrm{C}\right)$ & $T_{\mathrm{ps}}\left({ }^{\circ} \mathrm{C}\right)$ & $H_{\mathrm{s}}\left(\mathrm{W} / \mathrm{m}^{2}\right)$ & $F_{1}\left(\mathrm{~m}^{2} \mathrm{~K} / \mathrm{W}\right)$ \\
\hline 1 & 29.3 & 233 & 885 & 0.2302 \\
2 & 30.5 & 258 & 900 & 0.2528 \\
3 & 30.3 & 331 & 1035 & 0.2905 \\
\hline
\end{tabular}

power is $30 \mathrm{~W}$ for typical box-type solar cookers [4], while $F_{1}$ is 0.395 and $F_{2}$ is 0.654 for SK-14-type solar cooker with $1.54 \mathrm{~m}^{2}$ aperture area [12]. These parameters indicate that the dual parabolic cooker performance is comparable to that of SK-14 solar cooker.

\section{Determination of Exergy Efficiency and Quality Factor}

Exergy efficiency is often measured and reported for a given solar energy device as a measure of its potential for extracting heat from its surrounding environment $[19,22]$. As per definition, the exergy approaches zero as the device approaches an equilibrium state with the environment. Exergy of the solar radiation describes the exergy input to the solar energy device and is determined by measuring the solar radiation flux $\left(I^{\circ} A \Delta t\right)$ during the experiment and using the relation $[23,24]$ :

$$
E_{\mathrm{Xi}}=I^{\circ} A \Delta t\left[1+\left(\frac{T_{\mathrm{a}}}{T_{\mathrm{s}}}\right)^{4}\left(\frac{1}{3}\right)-\left(\frac{4}{3}\right)\left(\frac{T_{\mathrm{a}}}{T_{\mathrm{s}}}\right)\right],
$$

where $T_{\mathrm{a}}$ and $T_{\mathrm{s}}$, respectively, indicate the ambient air temperature during the experiment and the surface temperature of the sun, $I^{\circ}$ represents the measured solar radiation intensity perpendicular to the collector at a given instant, $\Delta t$ is the time interval between two readings, and $A$ indicates the aperture area of the solar collector under investigation. The exergy output power of the device can be evaluated as [23]

$$
E_{\mathrm{xo}}=E_{\text {out }}-M \cdot C \cdot T_{\mathrm{a}} \ln \left[\frac{T_{\mathrm{wf}}}{T_{\mathrm{wi}}}\right],
$$

where $T_{\mathrm{wi}}$ is the initial and $T_{\mathrm{wf}}$ is the final temperature of water (or any other material) placed inside the device. $M$ and $C$, respectively, represent the mass and the specific heat capacity of the material.

The exergy efficiency may therefore be evaluated as

$$
\psi=\frac{\left(M \cdot C \cdot\left[\left(T_{\mathrm{wf}}-T_{\mathrm{wi}}\right)-T_{\mathrm{a}} \ln \left(T_{\mathrm{wf}} / T_{\mathrm{wi}}\right)\right]\right) / \Delta t}{I^{0}\left[1+1 / 3\left(T_{\mathrm{a}} / T_{\mathrm{s}}\right)^{4}-4 / 3\left(T_{\mathrm{a}} / T_{\mathrm{s}}\right)\right] A} .
$$

Another important parameter is the exergy loss coefficient, which is determined by measuring the difference between exergy input and output and the temperature difference $\delta T$ between the water and the ambient air, defined as

$$
E_{\mathrm{X}_{\text {loss }}}=\frac{E_{\mathrm{xi}}-E_{\mathrm{xo}}}{A \cdot \Delta t \cdot \delta T}\left(\mathrm{~W} / \mathrm{m}^{2} \mathrm{~K}\right) .
$$


TABLE 3: Calculation of the second figure of merit and the cooking power for the dual parabolic reflector solar cooker for experiment numbers 4,5 , and 6 .

\begin{tabular}{lccccccccc}
\hline Exp. number & Effective aperture area $\left(\mathrm{m}^{2}\right)$ & $T_{\mathrm{wi}}\left({ }^{\circ} \mathrm{C}\right)$ & $T_{\mathrm{wf}}\left({ }^{\circ} \mathrm{C}\right)$ & $T_{\mathrm{av}}\left({ }^{\circ} \mathrm{C}\right)$ & $H_{\mathrm{av}}\left(\mathrm{W} / \mathrm{m}^{2}\right)$ & Duration $\tau(\operatorname{seconds})$ & $(M \cdot C)_{\mathrm{w}}(\mathrm{J} / \mathrm{K})$ & $F_{2}$ & $P(\mathrm{~W})$ \\
\hline 4 & 1.08 & 60 & 92 & 36.6 & 852.4 & 960 & 16,800 & 0.638 & 560 \\
5 & 1.08 & 60 & 91 & 41.8 & 814.6 & 1560 & 16,800 & 0.453 & 333.8 \\
6 & 1.08 & 65 & 91 & 42.8 & 990.2 & 780 & 16,800 & 0.610 & 560 \\
\hline
\end{tabular}

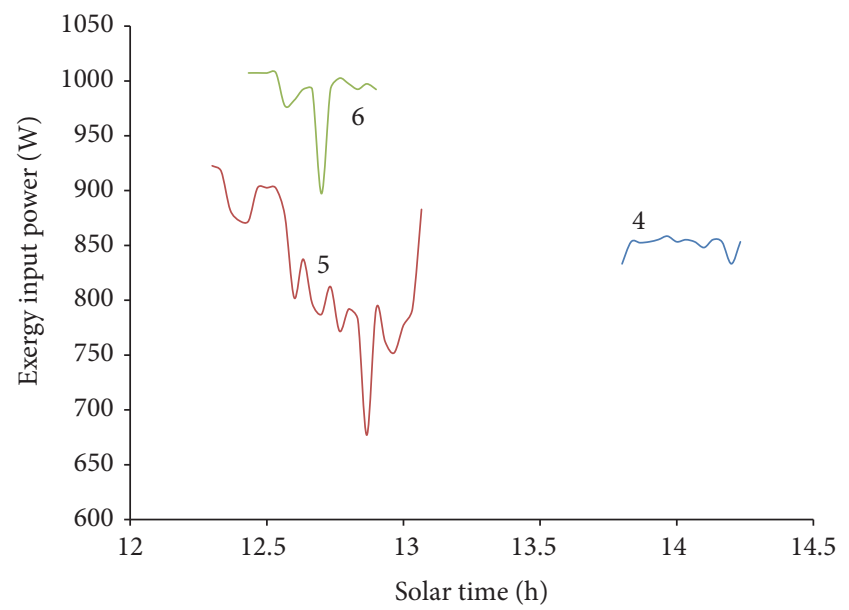

FIGURE 17: Exergy input power during the three experiments with $4 \mathrm{~kg}$ of water load. Curves are labeled according to the experiment number.

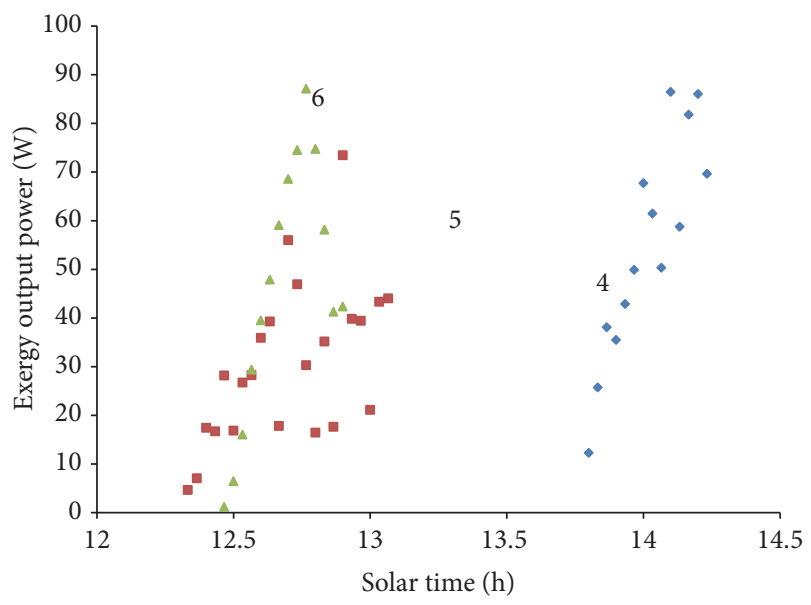

FIGURE 18: Exergy output power during the three experiments with $4 \mathrm{~kg}$ of water load. Blue points correspond to experiment number 4 , red to experiment number 5 , and green to experiment number 6 .

A plot of the exergy loss $\left(E_{\mathrm{xi}}-E_{\mathrm{xo}}\right)$ versus $\delta T$ can provide the overall heat loss coefficient of the cooker. Further, it has been proposed that a plot between the exergy output power and $\delta T$, fitted with a second order polynomial, can be used to infer the peak exergy power of the device during a particular experiment [25]. The plot may also be used to infer the temperature difference gap between

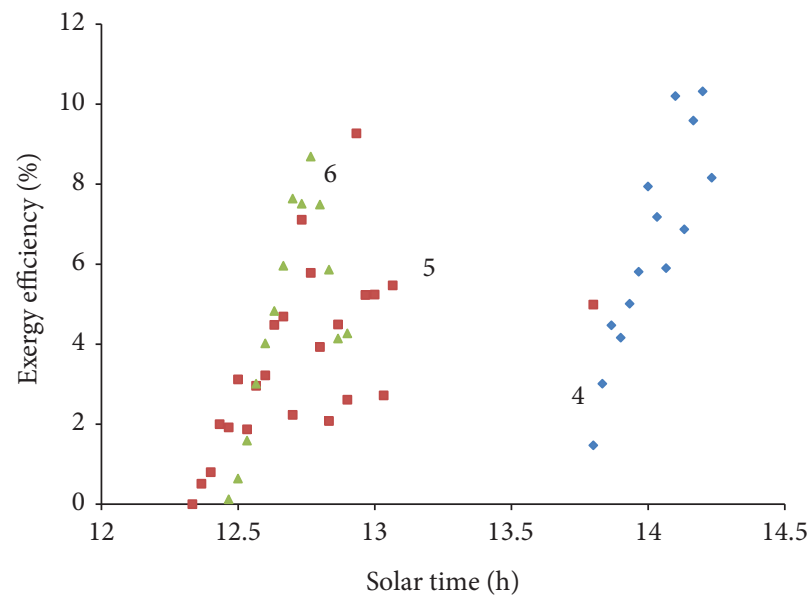

Figure 19: Efficiency of the exergy output power during the three experiments with $4 \mathrm{~kg}$ water load. Blue points correspond to experiment number 4 , red to experiment number 5 , and green to experiment number 6 .

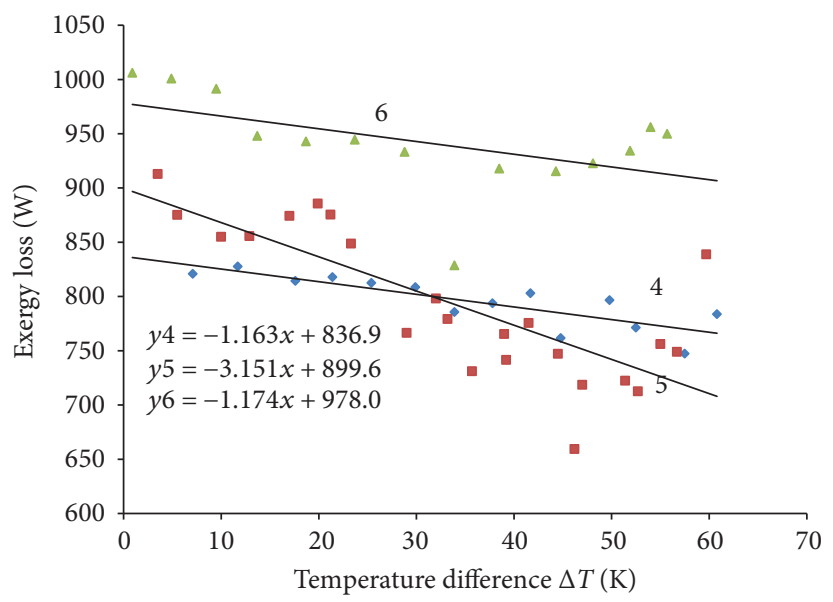

FIgURE 20: Least-squares fit to the exergy loss data for experiment numbers 4,5 , and 6 .

the temperatures corresponding to half exergy power points, on either side of the peak power point.

The exergy input power during the three experiments, as derived from (4), is shown in Figure 17.

The exergy output power during the three experiments, as extracted using 5 and fitted to a least-squares curve to show the trend with time, is shown in Figure 18, while the exergy efficiency is plotted in Figure 19. 


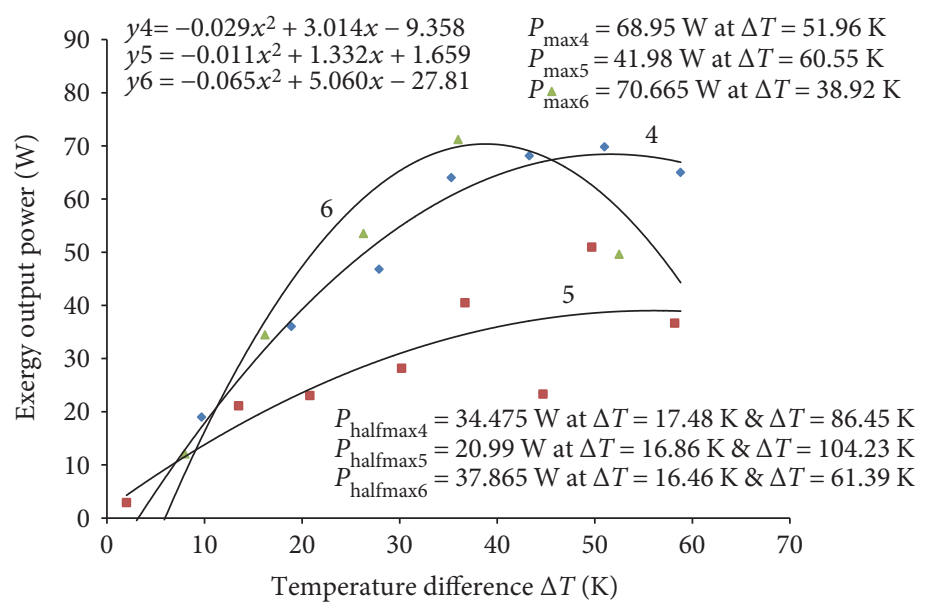

FiguRE 21: Exergy output power versus the temperature difference. Data are fitted with second order polynomials. Curves are labeled according to the experiment number.

TABLE 4: Various exergy-based performance measuring parameters for three types of solar cookers.

\begin{tabular}{|c|c|c|c|c|c|}
\hline Cooker parameter & Dual parabolic & SK-14 & Sheffler type & Box type & Vacuum tube type \\
\hline Slope of exergy loss curve $(\mathrm{W} / \mathrm{K})$ & 1.828 & 5.407 & 19.485 & 0.577 & 2.63 \\
\hline Aperture area $\left(\mathrm{m}^{2}\right)$ & 0.049 & 1.47 & 8.21 & 0.4326 & 0.107 \\
\hline Heat loss coefficient $\left(\mathrm{W} / \mathrm{K} \mathrm{m}^{2}\right)$ & 37.31 & 40.35 & 54.125 & 1.334 & 24.58 \\
\hline Specific heat loss coefficient $\left(\mathrm{W} / \mathrm{K} \mathrm{kg} \mathrm{m}^{2}\right)$ & 9.326 & 8.07 & 2.706 & 0.417 & 4.916 \\
\hline Peak exergy gain $(\mathrm{W})$ & 60.53 & 18.21 & 55.75 & 48.39 & 55.6 \\
\hline Exergy lost at peak exergy gain (W) & 805.87 & 171.79 & 560.606 & 377.90 & 1323.8 \\
\hline Quality factor & 0.077 & 0.106 & 0.099 & 0.1281 & 0.042 \\
\hline Temperature difference at peak power $(\mathrm{K})$ & 50.48 & 30.33 & 29.165 & 31.64 & 55.2 \\
\hline Temperature difference gap at half power $(\mathrm{K})$ & 72.1 & 40.374 & 39.62 & 41.76 & 38.75 \\
\hline $\begin{array}{l}\text { Product of temperature difference gap at half power to } \\
\text { peak power }(\mathrm{W} \cdot \mathrm{K})\end{array}$ & 4364.33 & 735.3 & 2208.815 & 2020.77 & 2154.5 \\
\hline
\end{tabular}

The exergy loss data $\left(E_{\mathrm{Xi}}-E_{\mathrm{xo}}\right)$ is plotted versus the temperature difference $\delta T$ in Figure 20, corresponding to experiment numbers 4,5 , and 6 . The data are fitted with linear curves. Heat loss coefficient $\left(\mathrm{W} / \mathrm{K} \mathrm{m}^{2}\right)$ of the cooker is extracted by dividing the slopes of these curves by the aperture area of the cooker, while the specific heat loss coefficient $\left(\mathrm{W} / \mathrm{K} \mathrm{kg} \mathrm{m}^{2}\right.$ ) is obtained by further division by the amount of water. The quality factor of the solar cooker may be evaluated by dividing the peak exergy gained to the exergy lost at that instant [25].

Figure 21 shows the graphs between the output exergy power $E_{\mathrm{xo}}$ and the temperature difference $\delta T$. The data are fitted to a second order polynomial, for all three experiments. The peak value of the exergy power and the temperature difference gaps corresponding to half peak power points have been extracted in each case.

The top three lines in the left of Figure 21 show the equations of the polynomial fits to the data for the three experiments. The bottom set of three lines shows the peak exergy power attained during each of the three experiments at a specific temperature difference. The third set of three lines at the right top of Figure 21 provides the temperature difference gaps at half peak exergy power points. The temperature difference gaps are 68.96, 102.43, and $44.93 \mathrm{~K}$, respectively.

The average value of the peak exergy power for the three experiments is $60.53 \mathrm{~W}$, while the average temperature difference gap at half peak power is $72.1 \mathrm{~K}$. The product of the peak power with the temperature difference gap is therefore $4364.33 \mathrm{~W} \cdot \mathrm{K}$. This value is by far the highest reported in literature, for any solar cooker. Table 4 summarizes the various exergy-based performance measuring parameters for these experiments and provides comparison of these parameters with those of other types of solar cookers [1, 3, 4, 25].

From Table 4, it may be concluded that the specific heat loss coefficient for parabolic-type solar cooker is comparable to that of SK-14. The quality factor of this cooker is higher than that of vacuum tube-type cooker and comparable to those of Scheffler and SK-14 types. However, the peak exergy gain, which determines the actual useful energy, is quite high, as compared to other types of solar cookers. Further, the temperature difference gap at half peak power and its product 
with the peak exergy gain are substantially higher compared to any other solar cooker reported so far. The average energy efficiency during the three experiments was $46.3 \%, 39.9 \%$, and $49.38 \%$, respectively. Due to design improvements in the present cooker, the maximum energy (49.38\%) and exergy (8-10\% from Figure 19) efficiencies have substantially improved compared to the results reported for a single parabolic trough cooker, where maximum energy efficiency was $15.7 \%$ and maximum exergy efficiency was $1.25 \%$ [23]. Similarly, these parameters are substantial improvements over SK-14 and Sheffler-type parabolic solar cookers [25].

\section{Conclusions}

This paper presents the results of an experimental investigation of an improved dual parabolic reflector solar cooker along with its construction details. The cooker has been explicitly designed from the point of view of a common user in terms of its usefulness and ease of transportation and handling, while addressing several other issues prevalent with such cookers. The cooker has been extensively tested under different load conditions and without load. All test results support it as a substantial improvement over other solar cookers in terms of its capacity of cooking all types of food as well as faster cooking with a view to its portability and lightweightiness. The various standard performance measuring parameters have been evaluated at a test load of $4 \mathrm{~kg}$ of water. The average cooking power of the cooker has been found to be $485 \mathrm{~W}$, while the maximum attainable temperatures with load approached $290^{\circ} \mathrm{C}$. Many cooking experiments like frying of eggs and French fries and making of bread have been conducted several times with great ease. The cooker has high exergy gain of up to $70 \mathrm{~W}$, with $8-10 \%$ maximum efficiency, while the thermal efficiency of the cooker is up to $49.4 \%$. The product of peak exergy power to the temperature difference gap, which is an important parameter for comparing the performance of solar cookers, has been found to be $4364.33 \mathrm{~W} \cdot \mathrm{K}$, which is by far the highest reported in the literature, for any solar cooker. The cooker is low cost (around US\$ 100) and easy to manufacture. It is quite ready for large scale dissemination.

\section{Conflicts of Interest}

The author declares that he has no conflicts of interest.

\section{Acknowledgments}

This work has been conducted at the Pakistan Council of Renewable Energy Technologies, Islamabad. The author is grateful to the council for extending its funds, facilities, and manpower for carrying out this study.

\section{References}

[1] S. Z. Farooqui, "A review of vacuum tube based solar cookers with the experimental determination of energy and exergy efficiencies of a single vacuum tube based prototype," Renewable and Sustainable Energy Reviews, vol. 31, pp. 439-445, 2014.
[2] R. M. Muthusivagami, R. Velraj, and R. Sethumadhavan, "Solar cookers with and without thermal storage-a review," Renewable and Sustainable Energy Reviews, vol. 14, no. 2, pp. 691-701, 2010.

[3] S. Z. Farooqui, "Impact of load variation on the energy and exergy efficiencies of a single vacuum tube based solar cooker," Renewable Energy, vol. 77, pp. 152-158, 2015.

[4] S. Z. Farooqui, "Angular optimization of dual booster mirror solar cookers - tracking free experiments with three different aspect ratios," Solar Energy, vol. 114, pp. 337-348, 2015.

[5] A. Balzar, P. Stumpf, S. Eckhoff, H. Ackermann, and M. Grupp, "A solar cooker using vacuum-tube collectors with integrated heat pipes," Solar Energy, vol. 58, no. 1-3, pp. 63-68, 1996.

[6] S. Z. Farooqui, "A vacuum tube based improved solar cooker," Sustainable Energy Technologies and Assessments, vol. 3, pp. 33-39, 2013.

[7] R. Kumar, R. S. Adhikari, H. P. Garg, and A. Kumar, "Thermal performance of a pressure cooker based on evacuated tube solar collector," Applied Thermal Engineering, vol. 21, pp. 1699-1706, 2001.

[8] K. Ashok, "A review of solar cooker designs, TIDE (TERI information digest on energy)," vol. 8, no. 1, pp. 1-37, 1998.

[9] S. C. Mullick, T. C. Kandpal, and S. Kumar, "Thermal test procedure for a paraboloid concentrator solar cooker," Solar Energy, vol. 46, no. 3, pp. 139-144, 1991.

[10] M. M. Rathore and R. M. Warkhedkar, "A review of solar cookers, international journal of modern trends in engineering and research, special issue of ICRTET'2015," vol. 2, no. 7, pp. 1997-2004, 2015.

[11] A. S. Ahmed, N. S. P. Rao, P. L. S. Murthy, and B. P. Terani, "Detail study of parabolic solar cooker SK-14," International Research Journal of Engineering and Technology, vol. 2, no. 4, pp. 24-27, 2015.

[12] A. Chandak, S. K. Somani, and P. M. Suryaji, "Comparative analysis of SK-14 and PRINCE-15 solar concentrators," in Proceedings of the World Congress on Engineering $2011 \mathrm{Vol}$ III WCE 2011, London, UK, July 6-8, 2011.

[13] W. Scheffler, "Introduction to the revolutionary Design of Scheffler Reflectors," Germany, November 2016, http://www. solare-bruecke.org.

[14] W. Scheffler, "The Scheffler reflector, Solare Brucke," November 2016, http://www.solare-bruecke.org/index.php/ en/die-scheffler-reflektoren.

[15] C. Reichl, F. Hengstberger, and C. Zauner, "Heat transfer mechanisms in a compound parabolic concentrator: comparison of computational fluid dynamics simulations to particle image velocimetry and local temperature measurements," Solar Energy, vol. 97, pp. 436-446, 2013.

[16] Y. Yoshiki Nishi and T. Sema, "Estimation of exergy efficiency of compound parabolic concentrator under time-varying cloud cover condition," Solar Energy, vol. 98, pp. 341348, 2013.

[17] W. B. Stine and M. Geyer, "“Power from the sun", J.T. Lyle Center for Regenerative Studies," John Wiley and Sons, Incorporated, 2001.

[18] Mylar, "All you need to know about," October 2016, https:// www.mjguide.com/tutorials/Lighting/1568.htm.

[19] P. A. Funk, "Evaluating the international standard procedure for testing solar cookers and reporting performance," Solar Energy, vol. 68, pp. 1-7, 2000. 
[20] S. C. Mullick and S. K. Kandpal, "Testing of box type solar cookers: second figure of merit - F2 and its variation with load and number of pots," Solar Energy, pp. 409-413, 1996.

[21] G. N. Tiwari, "Solar energy: fundamentals, design, modeling and applications," Alpha Science International, 2002.

[22] R. Petela, "Exergy of undiluted thermal radiation," Solar Energy, vol. 74, pp. 469-488, 2003.

[23] H. H. Ozturk, "Experimental determination of energy and exergy efficiency of the solar parabolic-cooker," Solar Energy, vol. 77, pp. 67-71, 2004.

[24] R. Petela, Engineering Thermodynamics of Thermal Radiation for Solar Power Utilization, McGraw-Hill, New York, 2010.

[25] N. Kumar, G. Vishwanath, and A. Gupta, "An exergy based unified test protocol for solar cookers of different geometries," Renewable Energy, vol. 44, pp. 457-462, 2012 

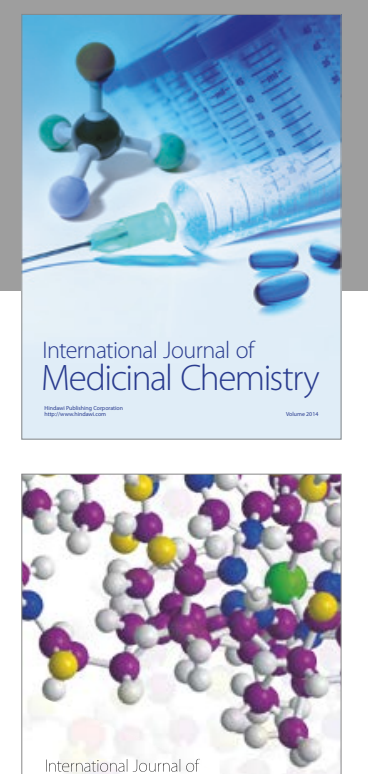

Carbohydrate Chemistry

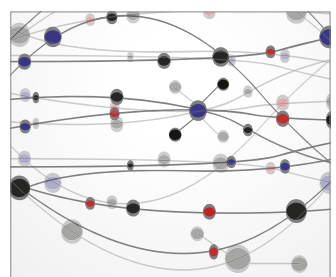

The Scientific World Journal
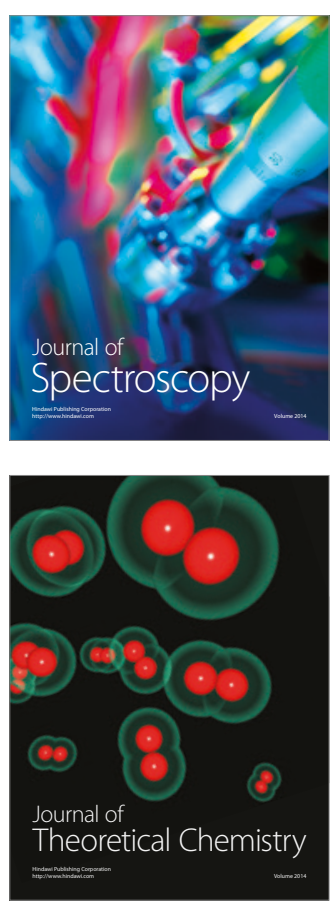
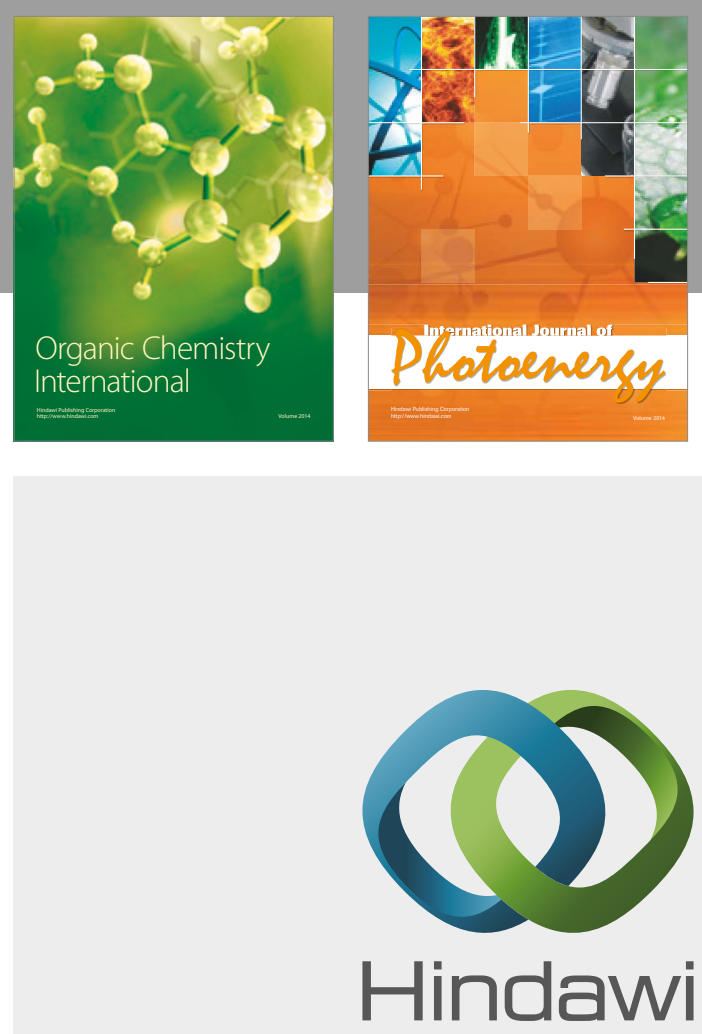

Submit your manuscripts at

https://www.hindawi.com

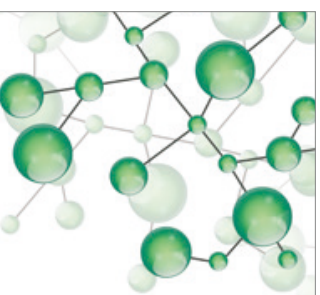

International Journal of

Inorganic Chemistry

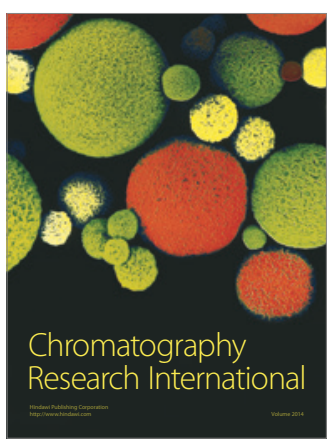

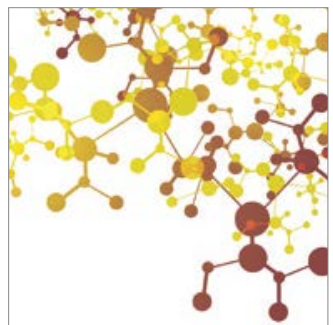

Applied Chemistry
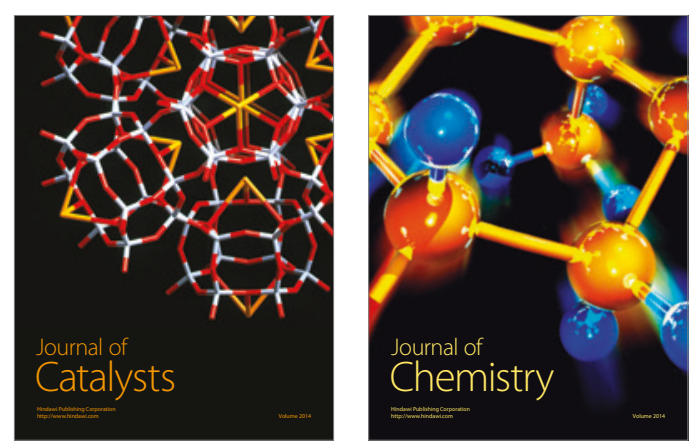
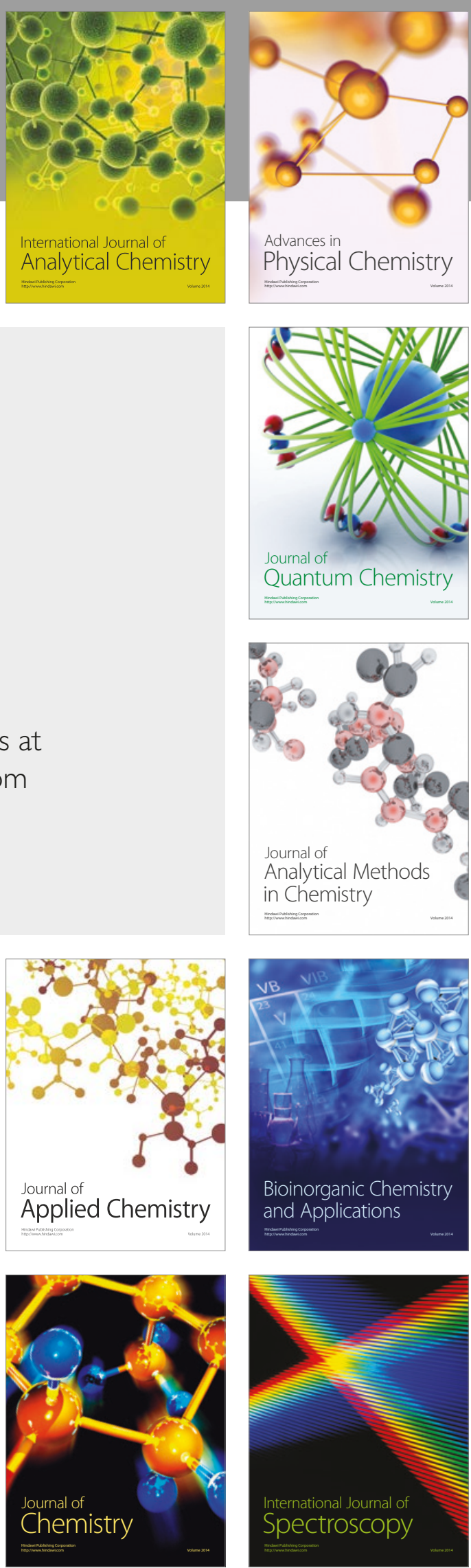